\title{
Independent associations of women's age at marriage and first pregnancy with their height in rural lowland Nepal
}

\begin{tabular}{|r|l|}
\hline Journal: & American Journal of Physical Anthropology \\
\hline Manuscript ID & AJPA-2020-00214.R1 \\
\hline Wiley - Manuscript type: & Research Article \\
\hline Date Submitted by the & n/a \\
\hline Complete List of Authors: & $\begin{array}{l}\text { Marphatia, Akanksha; University of Cambridge, Geography } \\
\text { Saville, Naomi; University College London, Institute for Global Health } \\
\text { Manandhar, Dharma; Mother and Infant Research Activities } \\
\text { Cortina-Borja, Mario; University College London, Great Ormond Streeet } \\
\text { Institute of Child Health } \\
\text { Reid, Alice; University of Cambridge, Geography } \\
\text { Wells, Jonathan; University College London, Great Ormond Street } \\
\text { Institute of Child Health }\end{array}$ \\
\hline $\begin{array}{r}\text { Subfield: Please select 2 } \\
\text { subfields. Select the main } \\
\text { subject first.: }\end{array}$ & $\begin{array}{l}\text { Adolescent marriage, Early pregnancy, Height, Social selection, Rural } \\
\text { lowland Nepal }\end{array}$ \\
\hline \multicolumn{2}{|c|}{ Theory biology [living humans; behavior, ecology, physiology, anatomy], } \\
\hline
\end{tabular}


Independent associations of women's age at marriage and first pregnancy with their height in rural lowland Nepal

Running title: Women's marriage and pregnancy age height Nepal

\author{
Akanksha A Marphatia $^{1 *}$, Naomi M Saville ${ }^{2}$, Dharma S Manandhar ${ }^{3}$, Mario Cortina-Borja ${ }^{4}$, \\ Alice M Reid ${ }^{1++}$ and Jonathan CK Wells ${ }^{4++}$ \\ ${ }^{++}$Joint senior authors \\ ${ }^{1}$ University of Cambridge, Department of Geography, 20 Downing Place, Cambridge CB2 \\ $3 E N, U K$ \\ ${ }^{2}$ University College London, Institute for Global Health, 30 Guilford Street, London WC1N \\ $1 E H, U K$ \\ ${ }^{3}$ Mother and Infant Research Activities, G.P.O. Box 921, Kathmandu, Nepal \\ ${ }^{4}$ University College London, Great Ormond Street Institute of Child Health, 30 Guilford \\ Street, London WCIN 1EH, UK \\ *Author for correspondence: Akanksha A Marphatia (aam54@cam.ac.uk)
}




\begin{abstract}
Objectives

In many South Asian communities, the majority of women are married during adolescence and reproduce before 20 years. Early reproduction may adversely affect maternal nutrition and linear growth, however whether early marriage has similar effects is unknown. Shorter women might also be preferentially chosen for earlier marriage. We hypothesised that early marriage and early pregnancy may each be associated with women's shorter height, independent of any selection effects.
\end{abstract}

\title{
Materials and Methods
}

We analysed cross-sectional data on 7,146 women aged 20-30 years from rural lowland Nepal. Linear regression models tested associations of early marriage and early reproduction with height, adjusting for women's education and husbands' characteristics (education and wealth) that might index preferential selection of short young women for marriage.

\section{Results}

Median ages at marriage and first pregnancy were 15 and 18 years respectively, with $20 \%$ pregnant $<16$ years. Both early marriage and early pregnancy were independently associated with shorter stature, accounting for a decrement of $1.4 \mathrm{~cm}$, which decreased to $1 \mathrm{~cm}$ after adjusting for women's education. Effects of early marriage and reproduction persisted after adjusting for the tendency of poorer and less educated men to marry young and short women, indicating a role for social selection.

\section{Discussion}

The decrements in height associated with early marriage and reproduction are indicative of broader adverse effects on maternal metabolism during a 'critical period' of growth and maturation in the life-course of women. Although the magnitudes of effect are relatively small, they affect large numbers of women in this population.

Keywords: Adolescent marriage; early pregnancy; height; social selection; rural lowland Nepal 


\section{INTRODUCTION}

In South Asia, there is a transactional nature to marriage, with its timing generally decided when the perceived costs of maintaining a daughter and investing in her education in the natal home exceed the benefits of her unpaid labour (Human Rights Watch, 2016). The prospective marital family's demand for a wife of a particular age and education level also influences her age at marriage (Human Rights Watch, 2016). Whilst both households stand to gain from this transaction, early (defined by the United Nations as $<18$ years (UN General Assembly, 2014)) marriage may adversely affect the health and human capital outcomes of both the woman and her subsequent children (Godha, Hotchkiss, \& Gage, 2013; Kim, Mejía-Guevara, Corsi, Aguayo, \& Subramanian, 2017; Raj et al., 2010).

Age at marriage may then have implications for maternal height, which in turn affects offspring's health. Across low and middle-income countries (LMICs), for example, maternal stature was inversely associated with offspring mortality risk, and the prevalence of underweight and stunting in infancy and childhood (Addo et al., 2013; Monden \& Smits, 2009; Özaltin, Hill, \& Subramanian, 2010). Studies from the Gambia have likewise found that in comparison to shorter women, taller women had later first births, fewer stillbirths, larger offspring and lower infant mortality (Allal, Sear, Prentice, \& Mace, 2004; Sear, 2010). Physiologically, shorter women have smaller pelvic dimensions, and this may contribute to intrauterine growth restriction and low birth weight in the next generation (Kozuki et al., 2015; Shirley, Cole, Arthurs, Clark, \& Wells, 2019).

Although adult height is a highly heritable trait (Fisher, 2019; Perkins, Subramanian, Davey Smith, \& Özaltin, 2016; Silventoinen, Helle, Nisén, Martikainen, \& Kaprio, 2013) it is also influenced by environmental and developmental factors (NCD Risk Factor Collaboration, 2016; Silventoinen, Kaprio, Lahelma, \& Koskenvuo, 2000), particularly those acting during early periods of development (Bogin, 1999; Perkins et al., 2016; Tanner, 1992). While much attention has been paid to 'critical windows' in foetal life and infancy, later developmental periods may also be important. For example, adolescent girls in rural Gambia showed substantial catch-up in height between the ages of 12 and 18 years (Prentice et al., 2013). Environmental stresses acting during adolescence might therefore constrain adolescent growth.

Addressing the association between early marriage and height builds on substantial prior work in the discipline of anthropometric history, which explicitly sought to use data on anthropometric outcomes to improve understanding of the adverse experiences of marginalised groups (Komlos, 1991, 1994; Steckel, 1995). Assessing trends in height over time to indicate changes in living conditions is particularly important for those low in social hierarchies, because conventional markers of living standards (e.g. wages or wealth) have little relevance (Tanner, 1990). For example, a study of $19^{\text {th }}$ century child factory workers interpreted girls' lower height-for-age score compared to boys as a marker of discrimination, potentially reflecting girls' higher susceptibility to disease, undernutrition, and the arduous physical nature of their work in both the factory and home (Horrell \& Oxley, 2016). In contemporary patriarchal societies, conversely, women have negligible opportunity to participate in the wage economy, and it is the norm for women to marry and reproduce before linear growth is completed. In both contexts, analysing anthropometric variability can provide a unique opportunity to explore asymmetric power relations in society and within families, which may have implications for health outcomes (Wells, 2016). 
Previous research has indicated that early age at reproduction may adversely impact women's growth. For example, Rah et al found that sub-optimal diets during pregnancy and lactation exacerbated Bangladeshi girls' poor nutritional status and hindered their linear growth (Rah et al., 2008). These authors estimated that the cessation of linear growth due to early pregnancy might result in an overall decrement of between 0.6 and $2.7 \mathrm{~cm}$ in attained height among 12 to 19 year old girls (Rah et al., 2008). In a similar study in Mexico City, pregnant adolescents showed no change in height between 20 weeks of gestation and 1 month post-partum, whereas non-pregnant adolescents matched by socioeconomic level, chronological age, menarche age and BMI gained $0.9 \mathrm{~cm}$ (Casanueva, Roselló-Soberón, De-Regil, Argüelles, \& Céspedes, 2006). Mechanistically, early reproduction may generate 'competition' for nutrients between the mother and foetus, and this may impair the growth of both mother and child (Allal et al., 2004; Scholl, Hediger, Schall, Khoo, \& Fischer, 1994; Sear, Allal, \& Mace, 2004; Stulp \& Barrett, 2016). These effects may be exacerbated in high-pathogen environments where infectious disease is largely untreated, as more energy may be allocated to immune defence, reducing its availability for growth (Wells \& Stock, 2020). However, evidence on the association of early pregnancy with height remains sparse.

Beyond these trade-offs, reproduction also reduces the allocation of energy to other metabolic functions such as defence, due to immune suppression, particularly in resource limited contexts (Jasienska, 2009). For example, in countries with high malaria burden, the frequency and severity of malaria is greater during pregnancy and early postpartum than before pregnancy (Diagne et al., 2000). Another component of defence is the stress response, which also has high energy costs, thereby reducing energy availability for other functions. For example, compared to lactating mothers in a control group, those who participated in a relaxation intervention had lower stress scores, lower breastmilk cortisol, and higher infant breastmilk intake and weight gain (Shukri et al., 2019).

Aside from early reproduction, whether early marriage is associated with shorter maternal height appears not to have been considered. In South Asia, marriage generally precedes childbearing and represents a cultural gateway to reproduction, and a substantial proportion of women are married during adolescence (MacQuarrie, 2016). In 2018, for example, $30 \%$ of women across South Asia aged 20-24 years had married $<18$ years and $8 \%<15$ years (UNICEF, 2020).

This paper therefore aims to investigate the independent associations of early age at marriage and first reproduction with women's height, in a cohort of women from rural lowland Nepal. Our models adjust for women's education as a potential confounder. Education is the only marker of socio-economic status in our dataset that reflects a woman's experience growing up in the natal household. Women with no or little schooling might be more likely to marry young, while the same educational traits might indicate family environments less favourable to growth (e.g. greater food insecurity or poorer sanitation, increasing exposure to infections). We further aim to investigate whether such associations are independent of husbands' characteristics (education, marital household wealth), which might contribute to selection effects (poorer men might marry women who are both younger and shorter).

\section{Women's early marriage and growth}

Beyond any mediating role of early reproduction, there are a number of different mechanisms through which early marriage may be associated with women's shorter height. While previous work has addressed the prospective association of adult height and the likelihood of women 
subsequently getting married and the timing of their marriage (Murasko, 2020; Smits \& Monden, 2012; Yamamura \& Tsutsui, 2017), our interest here is on the impact of marrying before adulthood on final height.

First, poverty and socio-cultural practices discriminating against women may result in decreased nutritional intake and poor growth of those women who are likely to be married early (Aurino, 2017; Bajracharya \& Amin, 2012). An analysis of Demographic Health Survey (DHS) data on married women aged 25-49 years from 54 LMICs found that on average, compared to the poorest quintile of wealth in the marital household, those in the first and second two richest quintiles were 2.0 and $1.0 \mathrm{~cm}$ taller respectively (Subramanian, Özaltin, \& Finlay, 2011). Similarly, compared to uneducated women, those with primary or secondary education were 0.16 and $1.33 \mathrm{~cm}$ taller (Subramanian et al., 2011). Since poverty may be an important correlate of early marriage (Bajracharya \& Amin, 2012; Samuels, Ghimire, Tamang, \& Uprety, 2017), it may also contribute to shorter height among those who marry early, though some historical studies have found the opposite (Baten \& Murray, 1998).

Second, there may be a genetic link between early puberty and shorter height. Girls who undergo puberty early tend to achieve shorter final height, reflecting their earlier growth cessation (Ong et al., 2009). In turn, studies suggest girls who experience puberty early may be more likely to marry earlier, as visible signs of sexual maturity may send a social signal for the readiness for marriage (and childbearing) (Chari, Heath, Maertens, \& Fatima, 2017; Raj et al., 2015). However, a study from Brazil found that poor early growth was associated with later puberty, but nevetheless with early childbearing (Wells, Cole, et al., 2019).

Third, early marriage might lead to the constraint of linear growth through psychosocial stress. During late adolescence, girls can gain between 5 and $7.6 \mathrm{~cm}$ (Spear, 2002; Viner et al., 2015), while in under-nourished populations, linear growth may continue beyond 20 years of age in order to recover from growth faltering in early life (Rah et al., 2008; Satyanarayana, Nadamuni Naidu, Swaminathan, \& Narasinga Rao, 1981; Wells, Wibaek, \& Poullas, 2018). In children, seminal work in German orphanages found that, despite abundant food provision, harsh and unsympathetic treatment caused distress and curtailed linear growth (Widdowson, 1951). More generally, growth in early life is widely recognised to reflect social conditions (Tanner, 1992). Little is known about this scenario in adolescents, however early marriage could exacerbate psychosocial stress. In a study in rural India, for example, early marriage, social isolation and adapting to new behaviours of the marital household increased distress and under-nutrition, partly because young married women chose to eat less because of their low mood (Chorghade, Barker, Kanade, \& Fall, 2006). Similarly, studies from Nepal have found social dynamics at meals such as young wives eating last and eating less than other family members may impact on nutrition (Clarke et al., 2014; Harris-Fry et al., 2018).

Fourth, an association between early marriage and growth might also emerge through social selection. In South Asian societies, covariance between husbands' and wives' characteristics emerges from household choices in arranged marriage agreements, potentially reflecting assortative mating by wealth or education (Smits, Ultee, \& Lammers, 1998), though it might also relate to direct concerns regarding height as a marker of social status, as reported in Pakistan (Ahmad, Gilbert, \& Naqui, 1985). A study on marriage markets in India found that women who were taller than average had a greater likelihood of marrying overall, and also of marrying after 16 years of age (Smits \& Monden, 2012). Both this study from India and another study from Italy also found taller women were more likely to pair with more educated husbands 
with a better labour market position (Ponzo \& Scoppa, 2015; Smits \& Monden, 2012). Theoretically, husbands seeking young brides might also directly seek short women, or indirectly pair with them by being unable to marry tall women. This might occur for example if poor men, also relatively short, preferred young wives and selected women from similar socio-economic backgrounds who were also short.

\section{MATERIALS AND METHODS}

\section{Study context}

This analysis is based on secondary analysis of data from the Low Birth Weight South Asia Trial (LBWSAT). The trial was approved by the Nepal Health Research Council and University College London ethics committees. Written informed consent was obtained from participants. This cluster randomised controlled (non-blinded) trial was conducted in the southern areas of Dhanusha and Mahottari districts, in Province 2 of the lowland Terai zone of Nepal. All married women and girls between the ages of 10-49 residing across 80 Village Development Committees (VDCs) were invited to take part in the trial. The main exclusion criteria was that neither they nor their husbands had undergone operative family planning (Saville et al., 2018, 2016). Between Dec 2013 and Feb 2015, 64,000 eligible women consented to menstrual monitoring and 24,682 pregnant women were recruited into the trial (Saville et al., 2016).

The main aims of LBWSAT were to assess the impact of pregnancy interventions on birth weight and infant growth (weight-for-age $z$-score, from 0-16 months). VDC clusters were randomly assigned to one of four interventions: (a) a behavioural change Participatory Learning and Action approach implemented through women's groups (PLA), (b) PLA and unconditional cash transfers provided to pregnant women, (c) PLA and a fortified blended food supplement given to pregnant women, or (d) Government of Nepal health services, which functioned as the control group. Data were collected by trained fieldworkers using oral questionnaires administered through smartphones.

\section{Variables analysed}

Our dependent variable is height $(\mathrm{cm})$. Our value for height collated measurements made either during early or late pregnancy, or during the postpartum period where pregnancy measurements were missing. We used height rather than weight as a marker of growth because weight may change substantially in association with pregnancy and other stimuli or stresses.

Our primary independent variables are women's age at marriage and at first pregnancy. Not every pregnancy necessarily resulted in a live birth. Women's marriage age and age of first pregnancy were recorded as integer values in running years, which were then converted to completed years (running years minus 1) during analysis. This is because most people count age in the year in which they are running rather than in completed years in this setting. Age at marriage was coded into five groups: $10-14$ years, 15 years, 16 years, 17 years and $\geq 18$ years. Age at first pregnancy was coded into three groups: $<16$ years, $16-17$ years and $\geq 18$ years.

Educational attainment (highest class completed in school) of both the wife and the husband was coded into four levels based on the structure of the education system in Nepal and also based on the distribution of data in our sample: none, primary (1-5 years), lower secondary (68 years) and secondary or higher ( $\geq 9$ years). 
Marital household assets reflect the context that women marry into, and also where the allocation of food, psychological well-being and the timing of pregnancy are negotiated. Our analyses used quartiles of marital household asset score, with 1 being the poorest and 4 being the richest. The household asset score was derived using principal component analysis based on the ownership of consumer goods including non-biomass fuel use, colour television, motorbike or computer, land ownership and household infrastructure: drinking water source, access to toilet facilities and electricity, roofing, walls and flooring materials. The first principal component had positive factor loadings for all 12 variables, accounting for $30.2 \%$ of the variability, compared to $10.5 \%$ and $8.5 \%$ from the second and third principal components respectively. We therefore used the first principal component as a marker of wealth.

\section{Adjusting height for age}

Since our interest is in examining how events in the past (marriage and first pregnancy) may be captured in women's phenotype (adult height), we focused on the 20 to 30-year age group. The lower age cut-off of 20 years was selected because this is when linear growth in this population is on average completed. In Supplementary Figure S1, loess scatterplot smoothers were fitted to explore associations between women's age and height for married women aged 14-30 years. The scale on the graph has been adjusted to show ages 16-24 years only, in order to emphasise the age at which height shows an age-associated inflexion in this population. Results show an increment in height up to the age of 20 years. Specifically, height increased by $0.07(95 \% \mathrm{CI}-0.05,0.19, p=0.287) \mathrm{cm}$ per year between the ages of $14-19$ years, and declined by $-0.07(95 \% \mathrm{CI}-0.12,-0.03, p=0.002) \mathrm{cm}$ per year between $20-30$ years. The upper age cut-off for the sample was selected as 30 years because of small numbers above this age.

In Supplementary Figure S2, loess scatterplot smoothers were fitted to explore associations between women's age and height for the selected sample of women aged 20-30 years used in our analysis. Results show a weak negative linear association between age and height for women aged 20-30 years, indicating a secular trend whereby more recent birth cohorts are taller than older cohorts. This cohort effect in height has been found in South Asia (NCD Risk Factor Collaboration, 2016; Subramanian et al., 2011). To adjust for this association, we standardized our outcome variable height by age, by taking the residuals from a regression of height as the dependent variable against age as the independent variable.

\section{Sample selection}

The flowchart in Supplementary Figure S3 illustrates the criteria used to select $n=7,146$ women aged 20-30 years for this analysis. Briefly, the study recruited 24,682 women into the trial. First, we excluded women who had more than one pregnancy during the trial $(n=408)$, to ensure they were not double-counted in our analyses. Second, we excluded women who were missing data on age $(n=36)$, and who were either $<20(n=9,950)$ and $>30(n=1,098)$ years of age. We excluded the younger women because they are likely to be growing still. Factors affecting age at marriage of older women may have also differed from those in the 10-year cohort we selected, and may be less relevant to current issues around age of marriage and first pregnancy.

Third, we excluded women missing data on their marriage age $(n=1,883)$, and those who either married very young $(<10$ years of age, $n=99)$, or at an older age ( $>22$ years of age, $n=67$ ) because of small numbers. These women were likely to be different than most other women in Province 2 of Nepal, who married at the median age of 16.5 years (Ministry of Health and Population, Nepal, New ERA, \& ICF International, 2017). Furthermore, in the Maithili- 
speaking Madhesi population of our study, married girls are not likely to move to their husbands' home until attaining menarche (Gram et al., 2017). Therefore, for the very young group, it was difficult to test whether marriage or first pregnancy age was associated with their height.

Fourth, we excluded women with missing data on first pregnancy age $(n=128)$, and with unusual timing of first pregnancy (either before marriage $(n=3)$, or $\geq 12$ years after marriage $(n=99)$ ). In 2016, women aged 25-49 years in Province 2 had median age at first birth of 19.2 years (Ministry of Health and Population, Nepal et al., 2017).

Fifth, we excluded women who were missing data on marital household assets $(n=3)$, or the location of the home where they were measured $(n=62)$, and if they were measured in their natal or other home $(n=1,461)$.

Sixth, we excluded women with missing data on height $(n=2,239)$. Supplementary Table S1 shows small differences between women with missing and available data. The small magnitude of the difference is not expected to bias our results.

\section{Statistical methods}

We first describe characteristics of our sample using frequencies and proportion (\%), mean and standard deviation (SD, for height only), or median and interquartile range (IQR) because of the skewed distribution of age, timing and asset data. To test for biases in continuous values of characteristics between women with missing and available data on height, we use nonparametric $K$ samples analysis of variance (Kruskal-Wallis test) to test for homogeneity of location. Spearman's coefficients describe correlations between continuous values of the variables used in analyses.

We then compare mean and standard error (SE) of women's height, age at marriage and first pregnancy by women's education. We also ask whether poorer and less educated men are more likely both to marry younger and shorter wives, which would indicate a role for social selection in the correlation between women's marriage age and height. We compare mean (SE) of women's height, age at marriage and age at first pregnancy by both husbands' education level and marital household assets. We test for trends in these associations using linear regression. These analyses test whether, as expected, these variables are potential confounders of the association between marriage age and height.

Next, we fit four Ordinary Least Squared (OLS) Linear Regression models in order to assess the separate, and combined (or independent) associations of age-standardised height residual with women's age at marriage (Model 1), women's age at first pregnancy (Model 2), and their combined associations (Model 3). Then, we introduce women's education (Model 4), as a potential confounder of the association between height and age at marriage or first pregnancy.

In addition, we present these OLS linear regression models for the uneducated women only, because they comprise a substantial proportion of our sample, and because in this group, women's height is entirely unconfounded by schooling.

We then further adjust our regression models of women's height for these two markers of the husbands' education and wealth, in order to take into account any social selection effects. To visualise these associations, we present 3D plots of the potential interactions between height 
and women's marriage age, pregnancy age and husbands' education level and assets. These 3D plots illustrate the combined social gradients in height associated with other factors.

In all of these models, we use women marrying at $\geq 18$ years, and having their first pregnancy at $\geq 18$ years, as the respective reference groups as we want to ascertain whether earlier timing of these events is associated with lower height. Selecting a group with later marriage or first pregnancy is not possible in this population due to small numbers, since early marriage and reproduction represent the norm. We use 'no education' and 'poor' households as the reference groups because we want to know whether attaining higher levels of these socio-economic characteristics benefited women's height.

We report regression coefficients and their 95\% confidence intervals (CI). We use the variance inflation factor (VIF) to test for multicollinearity. Although we report the adjusted $R^{2}$, multiplied by 100 to describe the proportion of the independent variable's variance explained by the inclusion of each predictor variable in each model, we do not discuss these values because our interest is in understanding the magnitude of the effect of the exposure at the population level, rather than to predict the height of individual women. Tests are conducted at a $5 \%$ two-sided significance level.

We also fit regression models adjusting for (unobserved) variability between the 80 geographic clusters, and trial arms, but as these factors have negligible effects and do not change our results substantively, we do not report the results.

Analyses are performed in Stata IC 15.1 (Stata Corp., College Station, TX) and SPSS 26 (IBM Corp., Armonk, NY).

\section{RESULTS}

\section{Description of sample}

Table 1 describes the characteristics of our sample. Mean height was $150.4 \mathrm{~cm}$ (SD 5.4). The median marital household asset score was -0.41 (IQR 2.4). About $37 \%$ of women had married during childhood, at ages 10-14 years, 51\% during adolescence (ages $15-17$ years) and $12 \%$ at ages $\geq 18$ years. About $20 \%$ of women had their first pregnancy at $<16$ years, $33 \%$ at ages 16 17 years and $48 \% \geq 18$ years. Almost $71 \%$ of women and $51 \%$ of husbands were uneducated compared to $12 \%$ and $22 \%$ with $\geq 9$ years of schooling respectively.

\section{Table 1 near here}

\section{Testing whether education and marital assets are potential confounders}

Table 2 explores if women's height, their age at marriage and first pregnancy increase in association with their own higher educational attainment, as well as their husbands' education and the marital household asset score. The results show statistically significant trends, with each of women's height, age at marriage and age at first pregnancy increasing in association with both women's and husbands' education, and with the marital household asset score.

\section{Table 2 near here}




\section{Quantifying the association between marriage and first pregnancy age with height}

The OLS linear regression models show the associations of women's height with their marriage age, and age at first pregnancy, adjusting for women's education.

\section{Table 3 near here}

Table 3, Model 1 shows that relative to marrying at $\geq 18$ years, marrying at 10-14 years was associated with a decrement in height, of $-1.20(95 \% \mathrm{CI}-1.61,-0.79) \mathrm{cm}$, and marrying at 15 and 16 years $-0.97(95 \% \mathrm{CI}-1.41,-0.54)$ and $-0.50(95 \% \mathrm{CI}-1.01,0.00) \mathrm{cm}$ respectively. The association of marrying at 17 years with height did not reach statistical significance $(-0.49 \mathrm{~cm}$, $95 \%$ CI $-0.99,0.00, p=0.052$ ). Model 2 shows that in comparison to having the first pregnancy at $\geq 18$ years, women having their first pregnancy at $<16$ years paid the biggest penalty in height, of $-0.87(95 \% \mathrm{CI}-1.21,-0.53) \mathrm{cm}$. First pregnancy between 16-17 years was also associated with lower height of $-0.34(95 \%$ CI $-0.62,-0.05) \mathrm{cm}$.

Model 3 shows that when considered in combination, early marriage at 10-14 years and 15 years had a stronger negative association, at $-0.99(95 \% \mathrm{CI}-1.48,-0.51) \mathrm{cm}$ and $-0.92(95 \% \mathrm{CI}$ $-1.40,-0.44) \mathrm{cm}$ respectively, with height, than early pregnancy. However, the independent negative association of early pregnancy at $<16$ years $(-0.42 \mathrm{~cm}, 95 \% \mathrm{CI}-0.84,0.00)$ with shorter height shows it also mattered. Neither marrying nor first pregnancy at 16-17 years reached statistical significance. The decrease in the coefficients in Model 3 compared to Models 1 and 2 suggests these factors may be covariant, as shown by their correlation $(0.62$, $p \leq 0.01)$.

Model 4 shows that relative to uneducated women, primary, lower secondary and secondary/higher education were associated with increments in height of $0.88(0.46,1.29) \mathrm{cm}$, $1.14(0.64,1.64) \mathrm{cm}$, and $1.56(1.16,1.97) \mathrm{cm}$ respectively. Adjusting for these associations, the coefficients for early marriage and first pregnancy decreased, with first pregnancy not reaching statistical significance. Marrying at 10-14 years and 15 years were still independently associated with decrements in height of $-0.58(95 \% \mathrm{CI}-1.07,-0.09) \mathrm{cm}$ and $-0.60(95 \% \mathrm{CI}-$ $1.08,-0.12) \mathrm{cm}$ respectively.

In summary, after adjusting for women's education, early marriage and first pregnancy $<16$ years accounted, in combination, for a decrement of $\sim 1.4 \mathrm{~cm}$ in height. This $1.4 \mathrm{~cm}$ decrease is derived by adding the effect of $\sim-1.00 \mathrm{~cm}$ for early marriage and $-0.42 \mathrm{~cm}$ for early pregnancy from Table 3, Model 3. There were no multicollinearity issues given the low VIF values (<1.6).

\section{For uneducated women only}

Next, we restrict our sample to the uneducated women only $(N=5,054)$, as their height is entirely independent of any benefits of attending school. Table 4 shows the results were similar to the full sample, with the association of early first pregnancy on height (Model 2) appearing to work through early marriage, which was associated with shorter height (Model 3). Model 3 shows that for uneducated women, marrying $<16$ years was associated with a $-0.63(95 \% \mathrm{CI}-$ $1.25,-0.01) \mathrm{cm}$ decrement in height. 


\section{Table 4 near here}

\section{Adjusting for husbands' education and marital household asset score}

We next consider whether these associations might be explained by selection effects, in other words, through certain types of husbands selecting both younger and shorter wives. As hypothesised, Table 2 showed that poorer men, and less educated men, tended to marry women when they were younger and also tended to pair with shorter women. We therefore further adjust Model 4 from Table 3 for husbands' education level and marital household asset score (Table 5). Table 5, Model 1 shows that independent of these husbands' traits, as well as women's education level, women's height remained significantly associated with both age at marriage and age at first pregnancy. Repeating this analysis among only the uneducated women reveals very similar findings (Model 2).

\section{Table 5 near here}

Table 5 Model 1 indicates that marrying at 10-14 years was associated with a decrement in height, of $-0.56(95 \% \mathrm{CI}-1.05,-0.07) \mathrm{cm}$, and marrying at 15 years $-0.60(-1.07,-0.11) \mathrm{cm}$. First pregnancy $<16$ years was associated with a decrement in height of -0.41 (95\% CI -0.83 , $0.00) \mathrm{cm}$. In comparison to Table 3 Model 1, the coefficients for women's age at marriage and first pregnancy decreased slightly, and each was still independently associated with height, after adjusting for women's education, their husbands' education and marital household assets.

In Model 2, the final adjusted model for uneducated women only shows marrying at 10-14 years was associated with a decrement in height, of $-0.58(95 \%$ CI $-1.19,-0.04, p=0.068) \mathrm{cm}$, and marrying at 15 years $-0.66(-1.28,-0.04) \mathrm{cm}$. First pregnancy $<16$ years was associated with a decrement in height of $-0.47(95 \% \mathrm{CI}-0.95,0.00, p=0.051) \mathrm{cm}$. In comparison to Table 4 , Model 3, the coefficients for marrying at 15 years increased slightly, and marrying at 10-14 years and first pregnancy $<16$ years were no longer statistically significant.

In summary, for the full sample, marriage and first pregnancy $<16$ years accounted, in combination, for a decrement of $\sim 1.0 \mathrm{~cm}$ in height after adjusting for education and marital assets. This $1.0 \mathrm{~cm}$ decrease is derived by adding the effect of $\sim-0.60$ for early marriage and -0.41 for early pregnancy from Table 5 , Model 1 . For uneducated women only, marriage at 15 years and first pregnancy $<16$ years accounted, in combination, for a decrement of $\sim 1.1 \mathrm{~cm}$ in height after adjusting for husbands' education and marital assets. This $1.1 \mathrm{~cm}$ decrease is derived by adding the effect of -0.66 for early marriage and -0.47 for early pregnancy from Table 5, Model 2. There were no multicollinearity issues given the low VIF values $(<1.7)$.

Interactive associations of women's height with their age at marriage and first pregnancy, stratified by husbands' traits

Figure 1 shows 3D plots of women's height in association with either their age at marriage or their age at first pregnancy, stratified by husbands' education level or household assets. (Figures 1a-d). (Tabulated values are provided in Supplementary Table S2). Overall, these plots help to visualise the difference between marrying early to an uneducated or poor man versus marrying later to an educated or wealthy man. They illustrate how both women's age at 
marriage and first pregnancy, and husbands' traits (e.g. education and wealth), are independently associated with height.

\section{Figure 1 near here}

Figure 1a shows that on average, women who were married $\geq 18$ years to a highly educated man were over $3 \mathrm{~cm}$ taller than women who married $<15$ years to an uneducated man. For any level of husbands' education, later marriage was associated with taller height. However, the slopes did not differ across the different groups, and the interaction term was not significant in the linear regression model (i.e. the association of women's height with her age at marriage or first pregnancy do not vary according to her husbands' traits). The same pattern of results was apparent for the interactive association of women's height with their age at marriage and the marital household asset score (Figure 1b), with their age at first pregnancy and their husbands' education level (Figure 1c) and with their age at first pregnancy and the marital household assets (Figure 1d).

\section{DISCUSSION}

This paper investigated the independent associations of women's early age at marriage and first pregnancy with their height, in a cohort of women from rural lowland Nepal. We found that shorter stature was independently associated with both early marriage and early pregnancy. These two factors accounted for a decrement of $1.4 \mathrm{~cm}$ in height, which decreased to $1 \mathrm{~cm}$ after adjusting for education and wealth.

Whilst adult height is considered a highly heritable trait (Fisher, 2019; Perkins et al., 2016; Silventoinen et al., 2013), we found as hypothesised that broader bio-social factors also shape women's height. Of particular interest, women's early age at marriage and first pregnancy were independently associated with shorter height. Although our study could not test the potential mechanisms explaining the association of early marriage and shorter height, previous research suggests these may include: poverty and socio-cultural discrimination against women, which may impact on their nutrition and growth (Bajracharya \& Amin, 2012; Subramanian et al., 2011); chronic under-nutrition during adolescence, especially during pubertal development (Rah et al., 2008; Sear et al., 2004); and psychological distress related to early marriage (Chorghade et al., 2006; Clarke et al., 2014; Harris-Fry et al., 2018). Some of these mechanisms could account for why women are already both short and young when they marry, whereas others could account for a constraint on growth after marriage. Puberty may also be associated with marriage and first pregnancy age, although evidence on the timing of these events is inconsistent (Chari et al., 2017; Raj et al., 2015; Wells, Cole, et al., 2019).

Beyond age at marriage, women who began reproduction at a young age also showed a small decrement in height. A potential mechanism could be the competition for nutrients between maternal and foetal development, as has been found in previous studies (Allal et al., 2004; Rah et al., 2008; Sear et al., 2004). From the perspective of evolutionary life history theory, maturation and growth may also be considered subject to a trade-off (McIntyre \& Kacerosky, 2011; Wells, Ness, Sear, Johnstone, \& Stearns, 2017). Women's reproductive fitness increases in association with height, however this is counter-balanced by the cumulative risk of mortality during the pre-reproductive period (Allal et al., 2004). The optimal time for ceasing to grow 
and starting to reproduce is therefore expected to represent a compromise between these variables, and it is then expected to vary in association with ecological conditions.

Beyond trade-offs between growth and reproduction in women, maternal stress can also reduce the energy available for investing in growth, maintenance or reproduction (Diagne et al., 2000; Jasienska, 2009; Shukri et al., 2019). Indeed, consistent with work on younger age groups (Widdowson, 1951), our findings suggest that psychosocial stress is a plausible mechanism contributing to the association of early marriage with shorter height. However, shorter height may also indicate an overall constraint on food consumption, and hence reduced availability of energy for all life history functions.

Given that height growth in adolescence is potentially substantial, and may also allow recovery from early growth faltering (Prentice et al., 2013), constraints on growth during this period may propagate long-term adverse effects on women's health and their reproductive biology (Kozuki et al., 2015), as well as survival and growth of the next generation (Özaltin et al., 2010). Both psychological stress and malnutrition are associated with higher oxidative stress, and both lower telomerase activity and shorter telomere length, which shape cell senescence and longevity, thereby promoting earlier onset of age-related diseases (Epel et al., 2004). Therefore, women who marry and reproduce early are not simply shorter and nor are they healthy, because the process of 'becoming shorter' i.e. growth faltering, acts as a sign of a more fundamental harmful process for health (Wells, Briend, et al., 2019).

Social selection may contribute to these associations, and we attempted to illustrate these issues using 3D plots. As expected, we found that men from households that had lower levels of wealth, or who had low levels of education, tended to marry women who were both young when they were married, and short. This indicates that part of the association between early marriage and short height may be explained by the poverty of both spouses, and reflects factors that influenced their linear growth before marriage. Consistent with this, we also found that uneducated women also had short height and tended to marry early, and these traits may reflect their natal household's lower socio-economic status, or willingness to invest in building her knowledge. However, adjusting for these socio-economic variables, decrements in height were still evident in association with both early marriage and early age at reproduction. Our 3D plots also showed independent associations of height with age at marriage, or with age at first pregnancy, with husbands' education or marital household wealth. Therefore, while social selection is certainly evident in our data, it does not fully explain the associations we detect, rather the two mechanisms appear to be independent.

Women's education and the timing of their marriage are likely to be closely related (Marphatia et al., 2020; Raj, McDougal, Silverman, \& Rusch, 2014) and this relationship may be bidirectional, although data on the timing of these decisions and events are usually not collected (Sekine \& Hodgkin, 2017; Wodon et al., 2017). Moreover, there was no confounding of women's education in the analysis of uneducated women, and the similar magnitude of the effect between the age variables and height of this group and the whole sample suggests the association of education with height is independent. Potential pathways include educated women being from wealthier and food-secure natal households, and experiencing better nutrition and growth in early life.

Following the rationale of the discipline of anthropometric history (Komlos, 1991, 1994; Steckel, 1995), our study provides a new perspective on the lived experience of women in a 
highly patriarchal society. Using height as an objective measure of health and living standards is crucial in the context of our study, because traditional measures of women's empowerment generally do not apply in this population (Gram et al., 2017). Collectively, women's shorter stature, lower education and earlier marriage are markers of their lower social status in both natal and marital homes. Whilst most studies of growth focus on infant nutrition and disease, we focus on women's experience during adolescence, which is also a crucial period for growth and maturity (Viner et al., 2015).

Although the magnitudes of effect that we describe in our study are relatively small, they indicate energetic stresses that affect large numbers of women in this population, given that $37 \%$ of the population were married before 15 years and $20 \%$ had had their first pregnancy before 16 years. Other studies have also linked shorter maternal height with poorer health and lower human capital among both women and their offspring (Addo et al., 2013; Monden \& Smits, 2009; Murasko, 2020; Özaltin et al., 2010; Sear et al., 2004; Subramanian et al., 2011). If the distribution of height is shifted downwards in the whole population only by $1 \mathrm{~cm}$, the absolute number of women pushed into a high-risk group of short stature may still be substantial.

Strengths of our study include large sample size. We also had data on age at marriage, which has not been collected in previous studies investigating associations between women's age at first pregnancy and their height. Limitations include missing data, but these do not result in bias. There may be potential error and recall bias due to women not knowing their exact age, or having a birth certificate. Age-related variables were measured to the completed year, so there was a loss of resolution over finely-grained results, but we can nevertheless detect patterns robustly. We also lacked data on other factors that could potentially relate to women's height such as their early growth patterns, age at menarche, and stressful life events; or their natal household assets and living environments. Some of these factors might reflect their mother's own nutritional or social status, and reproductive behaviour. Other limitations include the lack of data on husbands' age and height, without which we cannot establish the social aspects of short stature linked to early marriage relevant for both spouses. Data on these processes may explain a greater proportion of the variance in our results, potentially decreasing the magnitude of the effect of our explanatory variables. Our observational, cross-sectional study can investigate the factors associated with women's height, but we cannot establish causality.

\section{Conclusion}

We found that early marriage and pregnancy were each associated with women's shorter height, and in combination accounted for a decrement of $1.4 \mathrm{~cm}$, with this difference decreasing to $1.0 \mathrm{~cm}$ after adjusting for husbands' and wife's education and marital household assets. Although the magnitude of the association of exposures with maternal height in individuals was small, these decrements indicate broader adverse effects on women's metabolism during a sensitive period of development.

\section{Acknowledgements}

We are grateful to the women and their families for participating in the LBWSAT, and to the Dhanusha and Mahottari District Public Health Offices in Nepal for supporting implementation. We thank Mother and Infant Research Activities staff for data collection, and 
University College London Institute for Global Health team for their support (see (Saville et al., 2018) for details). This work was supported by the Leverhulme Trust (grant number 0326/015) and the National Institute for Health Research (NIHR) Great Ormond Street Hospital Biomedical Research Centre. The LBWSAT was funded by the Department for International Development (DFID) South Asian Research Hub (grant number PO 5675). The views expressed are those of the authors and not necessarily those of the National Health Service (NHS), the NIHR or the UK Department of Health. Funders played no role in the conceptualization, methodology, data curation, analysis or writing up of the results.

\section{Data availability statement}

Data analysed in this study were provided by UCL, Institute for Global Health in the UK and Mother and Infant Research Activities (MIRA), in Nepal. Requests to access the dataset, through a data sharing agreement, should be directed to Dr Naomi Saville, n.saville@ucl.ac.uk.

\section{References}

Addo, O. Y., Stein, A. D., Fall, C. H., Gigante, D. P., Guntupalli, A. M., Horta, B. L., ... Martorell, R. (2013). Maternal Height and Child Growth Patterns. The Journal of Pediatrics, 163(2), 549-554.e1. https://doi.org/10.1016/j.jpeds.2013.02.002

Ahmad, M., Gilbert, R. I., \& Naqui, A.-U.-N. (1985). Assortative mating for height in Pakistani arranged marriages. Journal of Biosocial Science, 17(2), 211-214. https://doi.org/10.1017/S0021932000015662

Allal, N., Sear, R., Prentice, A. M., \& Mace, R. (2004). An evolutionary model of stature, age at first birth and reproductive success in Gambian women. Proceedings of the Royal Society of London. Series B: Biological Sciences, 271(1538), 465-470. https://doi.org/doi: 10.1098/rspb.2003.2623

Aurino, E. (2017). Do boys eat better than girls in India? Longitudinal evidence on dietary diversity and food consumption disparities among children and adolescents. Economics \& Human Biology, 25, 99-111. https://doi.org/10.1016/j.ehb.2016.10.007 
Bajracharya, A., \& Amin, S. (2012). Poverty, marriage timing, and transitions to adulthood in Nepal. Studies in Family Planning, 43(2), 79-92. https://doi.org/10.1111/j.17284465.2012.00307.x

Baten, J., \& Murray, J. E. (1998). Women's Stature and Marriage Markets in Preindustrial Bavaria. Journal of Family History, 23(2), 124-135. https://doi.org/10.1177/036319909802300202

Bogin, B. (1999). Patterns of Human Growth. Cambridge University Press.

Casanueva, E., Roselló-Soberón, M. E., De-Regil, L. M., Argüelles, M. del C., \& Céspedes, M. I. (2006). Adolescents with Adequate Birth Weight Newborns Diminish Energy Expenditure and Cease Growth. The Journal of Nutrition, 136(10), 2498-2501. https://doi.org/10.1093/jn/136.10.2498

Chari, A. V., Heath, R., Maertens, A., \& Fatima, F. (2017). The causal effect of maternal age at marriage on child wellbeing: Evidence from India. Journal of Development Economics, 127(Supplement C), 42-55. https://doi.org/10.1016/j.jdeveco.2017.02.002

Chorghade, G., Barker, M., Kanade, S., \& Fall, C. (2006). Why are rural Indian women so thin? Findings from a village in Maharashtra. Public Health Nutrition, 9(01), 9-18. https://doi.org/10.1079/PHN2005762

Clarke, K., Saville, N., Bhandari, B., Giri, K., Ghising, M., Jha, M., ... Prost, A. (2014). Understanding psychological distress among mothers in rural Nepal: A qualitative grounded theory exploration. BMC Psychiatry, 14(1), 60. https://doi.org/10.1186/1471-244X-14-60

Diagne, N., Rogier, C., Sokhna, C. S., Tall, A., Fontenille, D., Roussilhon, C., ... Trape, J.-F. (2000). Increased Susceptibility to Malaria during the Early Postpartum Period. New England Journal of Medicine, 343(9), 598-603.

https://doi.org/10.1056/NEJM200008313430901 
Epel, E. S., Blackburn, E. H., Lin, J., Dhabhar, F. S., Adler, N. E., Morrow, J. D., \& Cawthon, R. M. (2004). Accelerated telomere shortening in response to life stress. Proceedings of the National Academy of Sciences, 101(49), 17312-17315. https://doi.org/10.1073/pnas.0407162101

Fisher, R. A. (2019). The causes of human variability. International Journal of Epidemiology, 48(1), 7-10. https://doi.org/10.1093/ije/dyw315

Godha, D., Hotchkiss, D., \& Gage, A. (2013). Association Between Child Marriage and Reproductive Health Outcomes and Service Utilization: A Multi-Country Study From South Asia. Journal of Adolescent Health, 52(5), 552-558. https://doi.org/10.1016/j.jadohealth.2013.01.021

Gram, L., Morrison, J., Sharma, N., Shrestha, B., Manandhar, D., Costello, A., ... SkordisWorrall, J. (2017). Validating an Agency-based Tool for Measuring Women's Empowerment in a Complex Public Health Trial in Rural Nepal. Journal of Human Development and Capabilities, 18(1), 107-135.

https://doi.org/10.1080/19452829.2016.1251403

Harris-Fry, H. A., Paudel, P., Shrestha, N., Harrisson, T., Beard, B. J., Jha, S., ... CortinaBorja, M. (2018). Status and determinants of intra-household food allocation in rural Nepal. European Journal of Clinical Nutrition, 1. https://doi.org/10.1038/s41430017-0063-0

Horrell, S., \& Oxley, D. (2016). Gender bias in nineteenth-century England: Evidence from factory children. Economics \& Human Biology, 22, 47-64. https://doi.org/10.1016/j.ehb.2016.03.006

Human Rights Watch. (2016). Our Time to Sing and Play: Child marriage in Nepal. USA: Human Rights Watch. 
Jasienska, G. (2009). Reproduction and lifespan: Trade-offs, overall energy budgets, intergenerational costs, and costs neglected by research. American Journal of Human Biology: The Official Journal of the Human Biology Association, 21(4), 524-532. https://doi.org/10.1002/ajhb.20931

Kim, R., Mejía-Guevara, I., Corsi, D. J., Aguayo, V. M., \& Subramanian, S. V. (2017). Relative importance of 13 correlates of child stunting in South Asia: Insights from nationally representative data from Afghanistan, Bangladesh, India, Nepal, and Pakistan. Social Science \& Medicine, 187, 144-154. https://doi.org/10.1016/j.socscimed.2017.06.017

Komlos, J. (1991). Anthropometric history: What is it? Journal of Social and Biological Structures, 14(3), 353-356. https://doi.org/10.1016/0140-1750(91)90006-C

Komlos, J. (1994). On the significance of anthropometric history. In Stature, Living Standards, and Economic Development: Essays in Anthropometric History (pp. 210 220). Chicago: USA: University of Chicago Press.

Kozuki, N., Katz, J., Lee, A. C. C., Vogel, J. P., Silveira, M. F., Sania, A., ... Child Health Epidemiology Reference Group Small-for-Gestational-Age/Preterm Birth Working Group. (2015). Short Maternal Stature Increases Risk of Small-for-Gestational-Age and Preterm Births in Low- and Middle-Income Countries: Individual Participant Data Meta-Analysis and Population Attributable Fraction. The Journal of Nutrition, 145(11), 2542-2550. https://doi.org/10.3945/jn.115.216374

MacQuarrie, K. (2016). Marriage and Fertility Dynamics: The Influence of Marriage Age on the Timing of First Birth and Birth-Spacing. (DHS Analytical Studies No. 56). Rockville: MD: ICF International. 
Marphatia, A. A., Saville, N. M., Amable, G. S., Manandhar, D. S., Cortina-Borja, M., Wells, J. C., \& Reid, A. M. (2020). How much education is needed to delay women's age at marriage and first pregnancy in lowland Nepal? Frontiers in Public Health, 7(396), 1-17. https://doi.org/10.3389/fpubh.2019.00396

McIntyre, M. H., \& Kacerosky, P. M. (2011). Age and size at maturity in women: A norm of reaction? American Journal of Human Biology, 23(3), 305-312. https://doi.org/10.1002/ajhb.21122

Ministry of Health and Population, Nepal, New ERA, \& ICF International. (2017). Nepal Demographic and Health Survey 2016. Kathmandu: Nepal: Ministry of Health.

Monden, C. W., \& Smits, J. (2009). Maternal height and child mortality in 42 developing countries. American Journal of Human Biology: The Official Journal of the Human Biology Association, 21(3), 305-311. https://doi.org/10.1002/ajhb.20860

Murasko, J. E. (2020). Height, Marriage, and Partner Characteristics for Women in Low- and Middle-Income Countries. Economics \& Human Biology, 38(100876), 1-11. https://doi.org/10.1016/j.ehb.2020.100876

NCD Risk Factor Collaboration. (2016). A century of trends in adult human height. Elife, 5, e13410.

Ong, K. K., Elks, C. E., Li, S., Zhao, J. H., Luan, J., Andersen, L. B., ... Wareham, N. J. (2009). Genetic variation in LIN28B is associated with the timing of puberty. Nature Genetics, 41(6), 729-733. https://doi.org/10.1038/ng.382

Özaltin, E., Hill, K., \& Subramanian, S. (2010). Association of Maternal Stature With Offspring Mortality, Underweight, and Stunting in Low- to Middle-Income Countries. JAMA: The Journal of the American Medical Association, 303(15), 1507-1516. https://doi.org/10.1001/jama.2010.450 
Perkins, J. M., Subramanian, S. V., Davey Smith, G., \& Özaltin, E. (2016). Adult height, nutrition, and population health. Nutrition Reviews, 74(3), 149-165. https://doi.org/10.1093/nutrit/nuv105

Ponzo, M., \& Scoppa, V. (2015). Trading height for education in the marriage market. American Journal of Human Biology, 27(2), 164-174. https://doi.org/10.1002/ajhb.22629

Prentice, A. M., Ward, K. A., Goldberg, G. R., Jarjou, L. M., Moore, S. E., Fulford, A. J., \& Prentice, A. (2013). Critical windows for nutritional interventions against stunting. The American Journal of Clinical Nutrition, 97(5), 911-918.

Rah, J. H., Christian, P., Shamim, A. A., Arju, U. T., Labrique, A. B., \& Rashid, M. (2008). Pregnancy and lactation hinder growth and nutritional status of adolescent girls in rural Bangladesh. The Journal of Nutrition, 138(8), 1505-1511. https://doi.org/10.1093/jn/138.8.1505

Raj, A., Ghule, M., Nair, S., Saggurti, N., Balaiah, D., \& Silverman, J. G. (2015). Age at menarche, education, and child marriage among young wives in rural Maharashtra, India. International Journal of Gynaecology and Obstetrics: The Official Organ of the International Federation of Gynaecology and Obstetrics, 131(1), 103-104. https://doi.org/10.1016/j.ijgo.2015.04.044

Raj, A., McDougal, L., Silverman, J. G., \& Rusch, M. L. A. (2014). Cross-Sectional Time Series Analysis of Associations between Education and Girl Child Marriage in Bangladesh, India, Nepal and Pakistan, 1991-2011. PLOS ONE, 9(9), e106210. https://doi.org/10.1371/journal.pone.0106210

Raj, A., Saggurti, N., Winter, M., Labonte, A., Decker, M., Balaiah, D., \& Silverman, J. (2010). The effect of maternal child marriage on morbidity and mortality of children 
under 5 in India: Cross sectional study of a nationally representative sample. $B M J$, 340, b4258. https://doi.org/10.1136/bmj.b4258

Samuels, F., Ghimire, A., Tamang, A., \& Uprety, S. (2017). Exploring Nepali adolescents' gendered experiences and perspectives [Research Brief]. London: UK: GAGE.

Satyanarayana, K., Nadamuni Naidu, A., Swaminathan, M. C., \& Narasinga Rao, B. S. (1981). Effect of nutritional deprivation in early childhood on later growth - A community study without intervention. The American Journal of Clinical Nutrition, 34(8), 1636-1637. https://doi.org/10.1093/ajcn/34.8.1636

Saville, N. M., Shrestha, B. P., Style, S., Harris-Fry, H., Beard, B. J., Sen, A., ... Sah, R. (2018). Impact on birth weight and child growth of Participatory Learning and Action women's groups with and without transfers of food or cash during pregnancy: Findings of the low birth weight South Asia cluster-randomised controlled trial (LBWSAT) in Nepal. PLOS ONE, 13(5), e0194064. https://doi.org/10.1371/journal.pone.0194064

Saville, N. M., Shrestha, B. P., Style, S., Harris-Fry, H., Beard, B. J., Sengupta, A., ... Pulkki-Brannstrom, A.-M. (2016). Protocol of the Low Birth Weight South Asia Trial (LBWSAT), a cluster-randomised controlled trial testing impact on birth weight and infant nutrition of participatory learning and action through women's groups, with and without unconditional transfers of fortified food or cash during pregnancy in Nepal. BMC Pregnancy and Childbirth, 16(1), 320. https://doi.org/10.1186/s12884016-1102-x

Scholl, T. O., Hediger, M. L., Schall, J. I., Khoo, C. S., \& Fischer, R. L. (1994). Maternal growth during pregnancy and the competition for nutrients. The American Journal of Clinical Nutrition, 60(2), 183-188. https://doi.org/10.1093/ajcn/60.2.183 
Sear, R. (2010). Height and Reproductive Success. In U. Frey, C. Störmer, \& K. Willführ (Eds.), Homo Novus-A Human Without Illusions (pp. 127-143). Berlin:Germany: Springer Berlin Heidelberg.

Sear, R., Allal, N., \& Mace, R. (2004). Height, marriage and reproductive success in Gambian women. Research in Economic Anthropology, 23, 203-224. https://doi.org/10.1007/s12110-006-1003-1

Sekine, K., \& Hodgkin, M. E. (2017). Effect of child marriage on girls' school dropout in Nepal: Analysis of data from the Multiple Indicator Cluster Survey 2014. PLOS ONE, 12(7), e0180176. https://doi.org/10.1371/journal.pone.0180176

Shirley, M. K., Cole, T. J., Arthurs, O. J., Clark, C. A., \& Wells, J. C. K. (2019).

Developmental origins of variability in pelvic dimensions: Evidence from nulliparous South Asian women in the United Kingdom. American Journal of Human Biology: The Official Journal of the Human Biology Council, e23340. https://doi.org/10.1002/ajhb.23340

Shukri, N. H. M., Wells, J., Eaton, S., Mukhtar, F., Petelin, A., Jenko-Pražnikar, Z., \& Fewtrell, M. (2019). Randomized controlled trial investigating the effects of a breastfeeding relaxation intervention on maternal psychological state, breast milk outcomes, and infant behavior and growth. The American Journal of Clinical Nutrition, 110(1), 121-130. https://doi.org/10.1093/ajcn/nqz033

Silventoinen, K., Helle, S., Nisén, J., Martikainen, P., \& Kaprio, J. (2013). Height, age at first birth, and lifetime reproductive success: A prospective cohort study of Finnish male and female twins. Twin Research and Human Genetics: The Official Journal of the International Society for Twin Studies, 16(2), 581-589. https://doi.org/10.1017/thg.2012.150 
Silventoinen, K., Kaprio, J., Lahelma, E., \& Koskenvuo, M. (2000). Relative effect of genetic and environmental factors on body height: Differences across birth cohorts among Finnish men and women. American Journal of Public Health, 90(4), 627-630. https://doi.org/10.2105/ajph.90.4.627

Smits, J., \& Monden, C. W. S. (2012). Taller Indian women are more successful at the marriage market. American Journal of Human Biology, 24(4), 473-478. https://doi.org/10.1002/ajhb.22248

Smits, J., Ultee, W., \& Lammers, J. (1998). Educational homogamy in 65 countries: An explanation of differences in openness using country-level explanatory variables. American Sociological Review, 264-285. https://doi.org/10.2307/2657327

Spear, B. A. (2002). Adolescent Growth and Development. Journal of the Academy of Nutrition and Dietetics, 102(3), S23-S29. https://doi.org/10.1016/S00028223(02)90418-9

Steckel, R. H. (1995). Stature and the Standard of Living. Journal of Economic Literature, 33(4), 1903-1940. https://www-jstor-org.ezp.lib.cam.ac.uk/stable/2729317

Stulp, G., \& Barrett, L. (2016). Evolutionary perspectives on human height variation. Biological Reviews, 91(1), 206-234. https://doi.org/10.1111/brv.12165

Subramanian, S., Özaltin, E., \& Finlay, J. (2011). Height of Nations: A Socioeconomic Analysis of Cohort Differences and Patterns among Women in 54 Low- to MiddleIncome Countries. PLoS ONE, 6(4), e18962. https://doi.org/10.1371/journal.pone.0018962

Tanner, J. (1990). Growth as a mirror of conditions in society. Stockholm: Sweden: Institute of Education Press.

Tanner, J. (1992). Growth as a measure of the nutritional and hygienic status of a population. Hormone Research, 38 Suppl 1, 106-115. https://doi.org/10.1159/000182580 
UN General Assembly. (2014). Resolution on Early, Child and Forced Marriage (UN General Assembly Resolution No. 68/148). New York: USA: UN General Assembly. UNICEF. (2020, February). Global database on child marriage. UNICEF. Retrieved from https://data.unicef.org/topic/child-protection/child-marriage/

Viner, R., Ross, D., Hardy, R., Kuh, D., Power, C., Johnson, A., ... Batty, G. (2015). Life course epidemiology: Recognising the importance of adolescence. Journal of Epidemiology and Community Health, jech-2014-205300. http://dx.doi.org/10.1136/jech-2014-205300

Wells, J. C. K. (2016). The Metabolic Ghetto: An Evolutionary Perspective on Nutrition, Power Relations and Chronic Disease. Cambridge: UK: Cambridge University Press.

Wells, J. C. K., Briend, A., Boyd, E. M., Berkely, J. A., Hall, A., Isanaka, S., ... Dolan, C. (2019). Beyond wasted and stunted-A major shift to fight child undernutrition. The Lancet Child \& Adolescent Health, 3(11), 831-834. https://doi.org/10.1016/S23524642(19)30244-5

Wells, J. C. K., Cole, T. J., Cortina-Borja, M., Sear, R., Leon, D. A., Marphatia, A. A., ... Gonçalves, H. (2019). Low maternal capital predicts life history trade-offs in daughters: Why adverse outcomes cluster in individuals. Frontiers in Public Health, 7, 206. https://doi.org/10.3389/fpubh.2019.00206

Wells, J. C. K., Ness, R. M., Sear, R., Johnstone, R. A., \& Stearns, S. C. (2017). Evolutionary public health: Introducing the concept. The Lancet, 390(10093), 500-509. https://doi.org/10.1016/S0140-6736(17)30572-X

Wells, J. C. K., \& Stock, J. T. (2020). Life History Transitions at the Origins of Agriculture: A Model for Understanding How Niche Construction Impacts Human Growth, Demography and Health. Frontiers in Endocrinology, 11, 325. https://doi.org/10.3389/fendo.2020.00325 
Wells, J. C. K., Wibaek, R., \& Poullas, M. (2018). The dual burden of malnutrition increases the risk of cesarean delivery: Evidence from India. Frontiers in Public Health, 6.

Widdowson, E. M. (1951). Mental Contentment and physical growth. The Lancet, 257(6668), 1316-1318. https://doi.org/10.1016/S0140-6736(51)91795-3

Wodon, Q. T., Male, C., Nayihouba, K. A., Onagoruwa, A. O., Savadogo, A., Yedan, A., ... Petroni, S. (2017). Economic impacts of child marriage: Global synthesis report (No. 116829; pp. 1-99). World Bank Group.

Yamamura, E., \& Tsutsui, Y. (2017). Comparing the role of the height of men and women in the marriage market. Economics \& Human Biology, 26, 42-50.

https://doi.org/10.1016/j.ehb.2017.02.006 


\section{Figure legends}

Figure 1.3D plots of interactive associations of women's height with their (a) husbands' education and women's age at marriage, (b) marital household asset score and women's age at marriage, (c) husbands' education and women's age at first pregnancy and (d) marital household's asset score and women's age at first pregnancy. 
Independent associations of women's age at marriage and first pregnancy with their height in rural lowland Nepal

\section{Revised Tables}

Table 1. Descriptive statistics

\begin{tabular}{|c|c|c|}
\hline \multirow[b]{2}{*}{ Dependent (outcome variable) } & \multicolumn{2}{|c|}{$\begin{array}{c}\text { Women aged } 20-30 \text { years } \\
\qquad(N=7,146)\end{array}$} \\
\hline & Mean & SD \\
\hline \multirow[t]{2}{*}{ Women's height $(\mathrm{cm})$} & 150.4 & 5.4 \\
\hline & Median & IQR \\
\hline Marital household asset score & -0.41 & 2.4 \\
\hline Independent (predictor variables) & Frequency & $\%$ \\
\hline \multicolumn{3}{|l|}{ Women's marriage age $(y)$} \\
\hline 10-14 years & 2,664 & 37.3 \\
\hline 15 years & 1,769 & 24.8 \\
\hline 16 years & 918 & 12.8 \\
\hline 17 years & 904 & 12.7 \\
\hline$\geq 18$ years & 891 & 12.5 \\
\hline \multicolumn{3}{|l|}{ Women's age at first pregnancy $(\mathrm{y})$} \\
\hline$<16$ years & 1,407 & 19.7 \\
\hline $16-17$ years & 2,328 & 32.6 \\
\hline$\geq 18$ years & 3,411 & 47.7 \\
\hline \multicolumn{3}{|l|}{ Women's education level (y) } \\
\hline None & 5,054 & 70.7 \\
\hline Primary $(1-5 y)$ & 752 & 10.5 \\
\hline Lower secondary (6-8y) & 494 & 6.9 \\
\hline Secondary or higher $(\geq 9 y)$ & 846 & 11.8 \\
\hline \multicolumn{3}{|l|}{ Husbands' education level (y) } \\
\hline None & 3,625 & 50.7 \\
\hline Primary (1-5y) & 923 & 12.9 \\
\hline Lower secondary (6-8y) & 1,024 & 14.3 \\
\hline Secondary or higher $(\geq 9 y)$ & 1,574 & 22.0 \\
\hline
\end{tabular}

$\mathrm{SD}$, standard deviation. IQR Interquartile Range. 
Table 2. Mean values, women's height, age at marriage and first pregnancy by their education

\begin{tabular}{|c|c|c|c|c|c|c|c|}
\hline \multirow[b]{2}{*}{$\begin{array}{l}\text { Women's } \\
\text { education (y) }\end{array}$} & \multirow[b]{2}{*}{$n$} & \multicolumn{2}{|c|}{$\begin{array}{c}\text { Women's height (cm) } \\
(N=7,146)\end{array}$} & \multicolumn{2}{|c|}{$\begin{array}{c}\begin{array}{c}\text { Women's age at marriage } \\
\text { (y) } \\
(N=7,146)\end{array} \\
\end{array}$} & \multicolumn{2}{|c|}{$\begin{array}{c}\text { Women's age at first } \\
\text { pregnancy }(y) \\
(N=7,146)\end{array}$} \\
\hline & & Mean & SE & Mean & SE & Mean & SE \\
\hline None & 5,054 & 150.0 & 0.08 & 15.0 & 0.03 & 17.5 & 0.04 \\
\hline $1-5$ years & 752 & 151.0 & 0.18 & 15.3 & 0.07 & 17.7 & 0.09 \\
\hline $6-8$ years & 494 & 151.3 & 0.23 & 15.6 & 0.08 & 17.7 & 0.10 \\
\hline$\geq 9$ years & 846 & 151.9 & 0.18 & 16.7 & 0.07 & 18.7 & 0.08 \\
\hline$p$ for trend & & \multicolumn{2}{|c|}{$<0.001$} & \multicolumn{2}{|c|}{$<0.001$} & \multicolumn{2}{|c|}{$<0.001$} \\
\hline \multicolumn{8}{|c|}{ Husbands' education (y) } \\
\hline None & 3,625 & 149.9 & 0.09 & 15.0 & 0.03 & 17.6 & 0.04 \\
\hline $1-5$ years & 923 & 150.3 & 0.18 & 15.1 & 0.06 & 17.6 & 0.08 \\
\hline $6-8$ years & 1,024 & 150.8 & 0.17 & 15.3 & 0.06 & 17.7 & 0.08 \\
\hline$\geq 9$ years & 1,574 & 151.6 & 0.13 & 15.9 & 0.05 & 18.0 & 0.06 \\
\hline$p$ for trend & & \multicolumn{2}{|c|}{$<0.001$} & \multicolumn{2}{|c|}{$<0.001$} & \multicolumn{2}{|c|}{$<0.001$} \\
\hline \multicolumn{8}{|c|}{ Marital household asset score } \\
\hline Quartile 1 & 1,816 & 149.5 & 0.13 & 15.1 & 0.04 & 17.5 & 0.06 \\
\hline Quartile 2 & 1,771 & 150.4 & 0.13 & 15.2 & 0.04 & 17.6 & 0.06 \\
\hline Quartile 3 & 1,758 & 150.6 & 0.12 & 15.3 & 0.04 & 17.7 & 0.06 \\
\hline Quartile 4 & 1,801 & 151.3 & 0.13 & 15.6 & 0.05 & 17.8 & 0.06 \\
\hline$p$ for trend & & \multicolumn{2}{|c|}{$<0.001$} & \multicolumn{2}{|c|}{$<0.001$} & \multicolumn{2}{|c|}{$<0.001$} \\
\hline
\end{tabular}

$\mathrm{N}$, number; SE, standard error. 


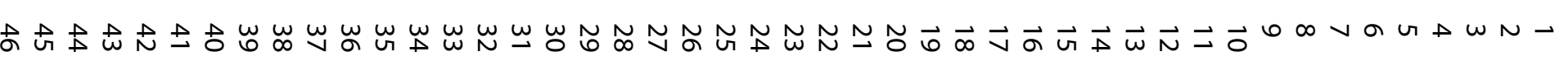

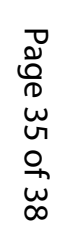

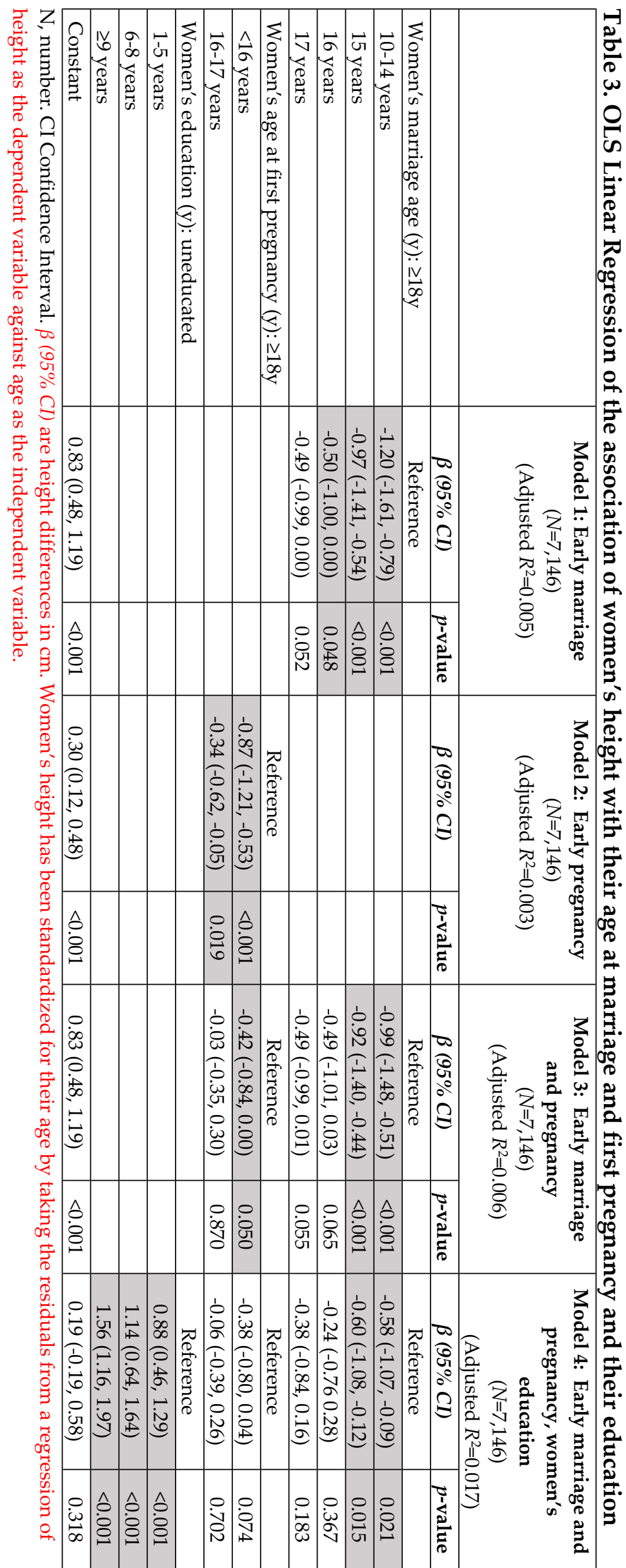

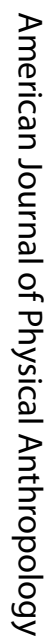


Table 4. OLS Linear Regression, association of uneducated women's height with their age at marriage and first pregnancy

\begin{tabular}{|c|c|c|c|c|c|c|}
\hline & $\begin{array}{c}\text { Model 1: } \\
\text { Early marriage } \\
(N=5,054) \\
\text { (Adjusted } \\
\left.R^{2}=0.002\right)\end{array}$ & & $\begin{array}{c}\text { Model 2: } \\
\text { Early pregnancy } \\
(N=5,054) \\
\text { (Adjusted } \\
\left.R^{2}=0.002\right)\end{array}$ & & $\begin{array}{c}\text { Model 3: } \\
\text { Early marriage and } \\
\text { pregnancy } \\
(N=5,054) \\
\left.\text { (Adjusted } R^{2}=0.002\right)\end{array}$ & \\
\hline & $\beta(95 \% C I)$ & $\begin{array}{c}p- \\
\text { value }\end{array}$ & $\beta(95 \% C I)$ & $\begin{array}{c}p- \\
\text { value }\end{array}$ & $\beta(95 \% C I)$ & $\begin{array}{c}p- \\
\text { value }\end{array}$ \\
\hline $\begin{array}{l}\text { Women's marriage } \\
\text { age }(y): \geq 18 y\end{array}$ & Reference & & & & Reference & \\
\hline $10-14$ years & $-0.78(-1.32,-0.24)$ & 0.005 & & & $-0.54(-1.16,0.07)$ & 0.085 \\
\hline 15 years & $-0.71(-1.29,-0.13)$ & 0.016 & & & $-0.63(-1.25,-0.01)$ & 0.046 \\
\hline 16 years & $-0.19(-0.85,0.46)$ & 0.559 & & & $-0.16(-0.84,0.51)$ & 0.635 \\
\hline 17 years & $-0.27(-0.93,0.40)$ & 0.432 & & & $-0.26(-0.93,0.41)$ & 0.445 \\
\hline $\begin{array}{l}\text { Women's age at first } \\
\text { pregnancy }(y): \geq 18 y\end{array}$ & & & Reference & & Reference & \\
\hline$<16$ years & & & $-0.67(-1.05,-0.28)$ & 0.001 & $-0.44(-0.92,0.03)$ & 0.069 \\
\hline 16-17 years & & & $-0.24(-0.59,0.10)$ & 0.165 & $-0.07(-0.46,0.32)$ & 0.734 \\
\hline Constant & $0.18(-0.31,0.68)$ & 0.460 & $-0.14(-0.37,0.08)$ & 0.212 & $0.18(-0.31,0.68)$ & 0.460 \\
\hline
\end{tabular}

$\mathrm{N}$, number. CI Confidence Interval. $\beta(95 \% \mathrm{CI})$ are height differences in $\mathrm{cm}$. Women's height has been standardized for their age by taking the residuals from a regression of height as the dependent variable against age as the independent variable. 
Table 5. OLS Linear Regression of the association of women's height with their age at marriage and first pregnancy, adjusting for husbands' education and marital household assets

\begin{tabular}{|c|c|c|c|c|}
\hline & \multicolumn{2}{|c|}{$\begin{array}{l}\text { Model 1: All women } \\
\qquad(N=7,146) \\
\left.\text { (Adjusted } R^{2}=0.024\right)\end{array}$} & \multicolumn{2}{|c|}{$\begin{array}{c}\text { Model 2: Only uneducated } \\
\text { women }(N=5,054) \\
\left.\text { (Adjusted } R^{2}=0.013\right)\end{array}$} \\
\hline & $\beta(95 \% C I)$ & $\begin{array}{c}p- \\
\text { value }\end{array}$ & $\beta(95 \% C I)$ & $p$-value \\
\hline Women's marriage age $(\mathrm{y}): \geq 18 \mathrm{y}$ & Reference & & Reference & \\
\hline $10-14$ years & $-0.56(-1.05,-0.07)$ & 0.025 & $-0.58(-1.19,0.04)$ & 0.068 \\
\hline 15 years & $-0.60(-1.07,-0.11)$ & 0.016 & $-0.66(-1.28,-0.04)$ & 0.036 \\
\hline 16 years & $-0.25(-0.78,0.27)$ & 0.338 & $0.22(-0.90,0.45)$ & 0.514 \\
\hline 17 years & $-0.36(-0.86,0.14)$ & 0.162 & $-0.30(-0.97,0.36)$ & 0.374 \\
\hline Women's age at first pregnancy $(y): \geq 18 y$ & Reference & & Reference & \\
\hline$<16$ years & $-0.41(-0.83,0.00)$ & 0.050 & $-0.47(-0.95,0.00)$ & 0.051 \\
\hline 16-17 years & $-0.08(-0.40,0.24)$ & 0.623 & $-0.07(-0.46,0.31)$ & 0.703 \\
\hline Women's education (y): uneducated & Reference & & na & \\
\hline $1-5$ years & $0.51(0.08,0.93)$ & $<0.0001$ & & \\
\hline $6-8$ years & $0.58(0.05,1.10)$ & $<0.0001$ & & \\
\hline$\geq 9$ years & $0.68(0.19,1.17)$ & $<0.0001$ & & \\
\hline Husbands' education (y): uneducated & Reference & & Reference & \\
\hline $1-5$ years & $0.17(-0.22,0.56)$ & 0.388 & $0.25(-0.19,0.70)$ & 0.262 \\
\hline 6-8 years & $0.38(-0.01,0.77)$ & 0.057 & $0.34(-0.14,0.82)$ & 0.160 \\
\hline$\geq 9$ years & $0.74(0.34,1.14)$ & $<0.001$ & $0.92(0.39,1.45)$ & $<0.001$ \\
\hline $\begin{array}{l}\text { Marital household assets: First quartile } \\
\text { (poorest) }\end{array}$ & Reference & & Reference & \\
\hline Second quartile & $0.68(0.33,1.03)$ & $<0.001$ & $0.720 .33,1.11)$ & $<0.001$ \\
\hline Third quartile & $0.74(0.37,1.10)$ & $<0.001$ & $0.80(0.381 .21)$ & $<0.001$ \\
\hline Fourth quartile (richest) & $1.13(0.75,1.52)$ & $<0.001$ & $1.31(0.85,1.77)$ & $<0.001$ \\
\hline Constant & $-0.49(-0.92,-0.06)$ & 0.026 & $-0.54(-1.08,-0.01)$ & 0.046 \\
\hline
\end{tabular}

$\mathrm{N}$, number. CI Confidence Interval. $\beta(95 \% \mathrm{CI})$ are height differences in $\mathrm{cm}$. Women's height has been standardized for their age by taking the residuals from a regression of height as the dependent variable against age as the independent variable. 


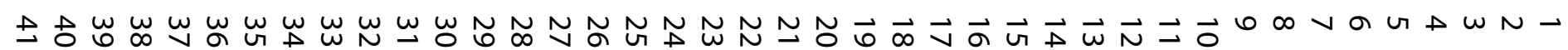
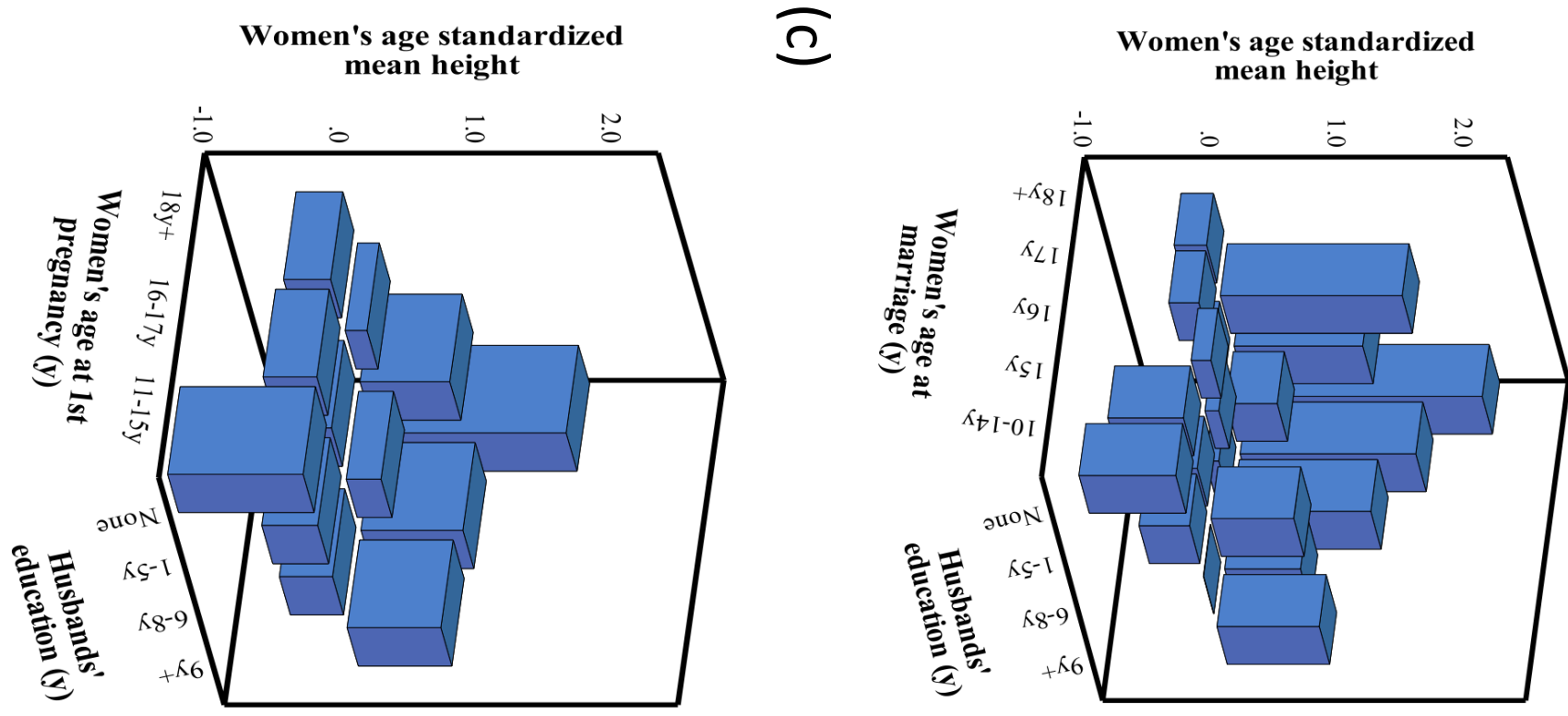

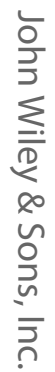
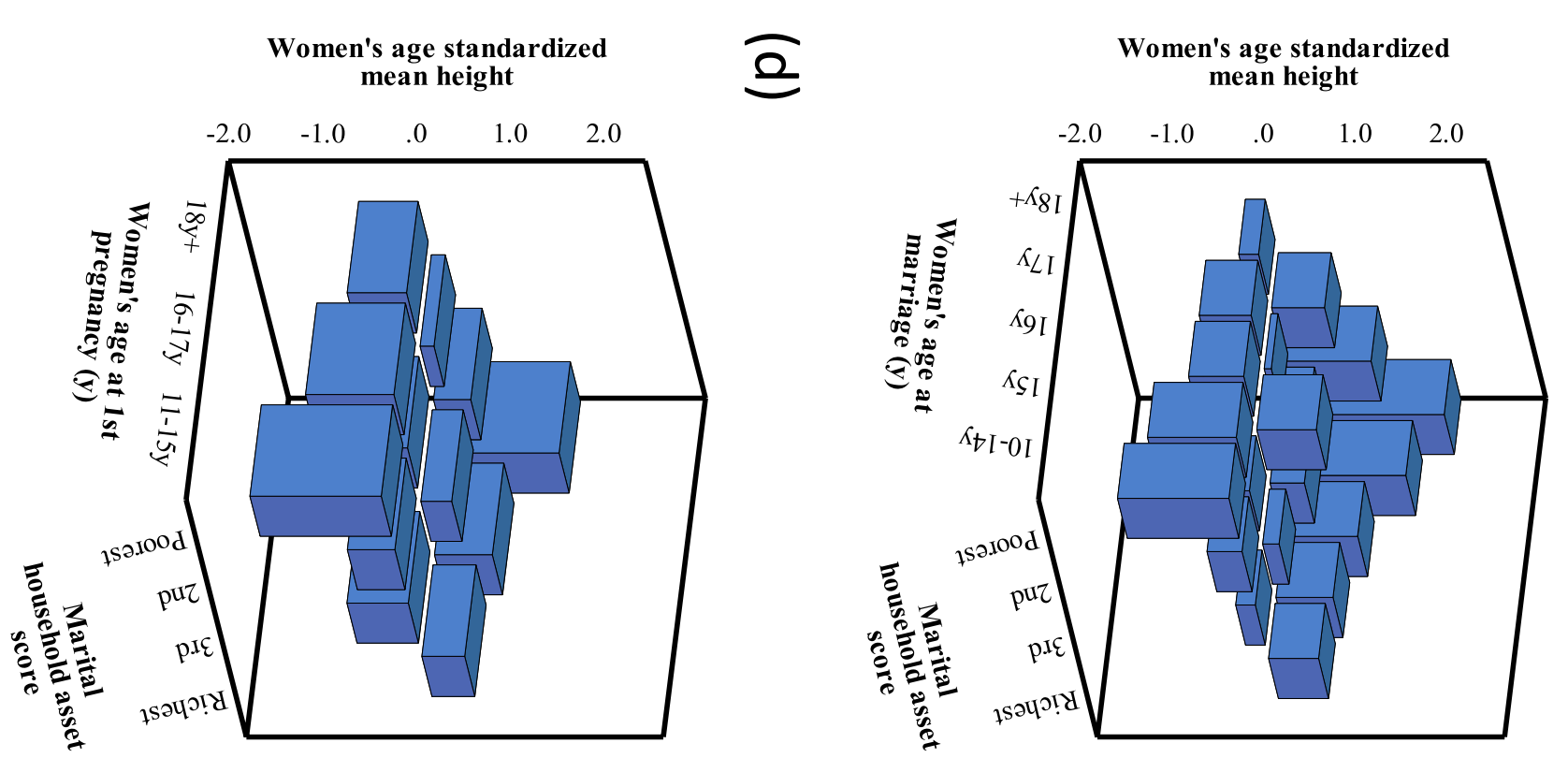